Check for updates

Cite this: Org. Biomol. Chem., 2018, 16,750

\title{
Bioinspired total synthesis of tetrahydrofuran lignans by tandem nucleophilic addition/redox isomerization/oxidative coupling and cycloetherification reactions as key steps $\uparrow$
}

\author{
Pratap R. Jagtap, ${ }^{a}$ Ivana Císařováb and Ullrich Jahn (D)*a \\ A very short three-step approach to trans,trans,trans-2,5-diaryl-3,4-dimethyltetrahydrofuran lignans is \\ reported. The carbon skeleton is assembled in a single step based on an unprecedented tandem reaction \\ consisting of 1,2-addition of aryllithium reagents to $\alpha, \beta$-unsaturated aldehydes, ruthenium-catalyzed \\ redox isomerization of the resulting alkoxides to enolates and their dimerization triggered by single elec- \\ tron oxidation. The resulting 2,3-dialkyl-1,4-diketones form with moderate to good $d / l$-diastereo- \\ selectivity and are transformed to the target tetrahydrofuran lignans by reduction and diastereoselective \\ cycloetherification.
}

Received 20th November 2017, Accepted 8th December 2017

DOI: $10.1039 / c 70 b 02848 b$

rsc.li/obc

\section{Introduction}

Tetrahydrofuran lignans I-III are a large class of plant-based natural products (Scheme 1). ${ }^{1}$ They display species-specific defined substitution patterns and stereochemistry at the carbon atoms of the tetrahydrofuran rings. All THF lignans are thought to result from the same achiral precursors coniferyl alcohol IV $(\mathrm{R}=\mathrm{OH})$ or isoeugenol $(\mathrm{R}=\mathrm{H}){ }^{2}$ They are subject to oxidatively generate radicals $\mathbf{V}$, which couple to quinone methides VII via presumed arrangement VI in the active site of a dirigent protein. This sets the absolute stereochemistry at C3-C4 and allows subsequent cyclization to pinoresinol VIII, which is enzymatically transformed to lignans of types I and II. In contrast, hydration of dimeric VII provides the diastereomeric lignans of type III. It is noteworthy that tetrahydrofuran lignans III with the 3,4-cis- as well as 3,4-trans-dimethyl configuration were isolated and the relative configuration of the 2,5diaryl units with respect to the 3,4-positions is variable. Even a THF lignan with the sterically most demanding all-cis-configuration has been very recently isolated; $;^{1 f}$ thus, all relative and absolute configurations at the tetrahydrofuran ring are

\footnotetext{
${ }^{a}$ Institute of Organic Chemistry and Biochemistry of the Czech Academy of Sciences, Flemingovo náměstí 2, 16610 Prague, Czech Republic.

E-mail: ullrich.jahn@uochb.cas.cz

${ }^{b}$ Department of Inorganic Chemistry, Charles University in Prague, Hlavova 8, 12843 Prague 2, Czech Republic

$\dagger$ Electronic supplementary information (ESI) available: Experimental procedures, analytical characterization and copies of ${ }^{1} \mathrm{H}$ and ${ }^{13} \mathrm{C}$ NMR spectra of all compounds. CCDC 1484493, 1484494 and 1538562-1538564. For ESI and crystallographic data in CIF or other electronic format see DOI: 10.1039/c7ob02848b
}

found in these natural products showing that the coupling stereochemistry of radicals VI to quinone methides VII varies strongly, and also suggesting strong constraints in the subsequent hydration step from VII to tetrahydrofurans III. Since tetrahydrofuran lignans display diverse and promising biological activities, ${ }^{1}$ but nature typically provides only minute quantities, total synthesis is the only way to gain access to larger amounts of the natural products.

Common approaches to THF lignans of type III involve alkylation of enolates $\mathbf{B}$ by bromo ketones A, providing $d, l$ diketones with good selectivity (Scheme 2). ${ }^{3}$ Their subsequent reductive cyclization gave predominately cis,trans,trans-2,5diaryl-3,4-dimethyltetrahydrofurans. Conjugate addition to $\mathbf{C}$ and cyclization furnished two diastereomers of tetrahydrofuran lignans with a cis,trans,cis configuration in a $7: 1$ ratio, ${ }^{4 a}$ as well as with trans,trans,trans or cis,trans,trans configuration depending on the configuration of the acyclic precursor, which had to be separated from a 2.5:1 diastereomeric mixture before. ${ }^{4 b}$ A conjugate addition/radical cyclization approach of $\mathbf{D}$ and $\mathbf{E}$ provided tetrahydrofuran lignans with variable 2,5trans- as well as 2,5-cis-selectivity, but low 3,4-diastereoselectivity. ${ }^{5}$ Oxidative coupling reactions of cinnamic acid derivatives gave low yields of 3,4-trans-tetrahydrofuran lignans with variable 2,5-diastereoselectivity. ${ }^{6}$ An azonia-Claisen rearrangement of tertiary crotylamines $\mathbf{F}$ and propionyl chloride $\mathbf{G}$ followed by a twofold addition provided trans,trans,translignans with high diastereoselectivity, but over eight steps. ${ }^{7}$

Recently, we applied redox isomerizations ${ }^{8}$ as an atomeconomical reactive intermediate switch from alkoxide anions to enolates. They served well in a unique tandem organometallic addition of aryllithium reagents 1 to $\alpha, \beta$-unsaturated 

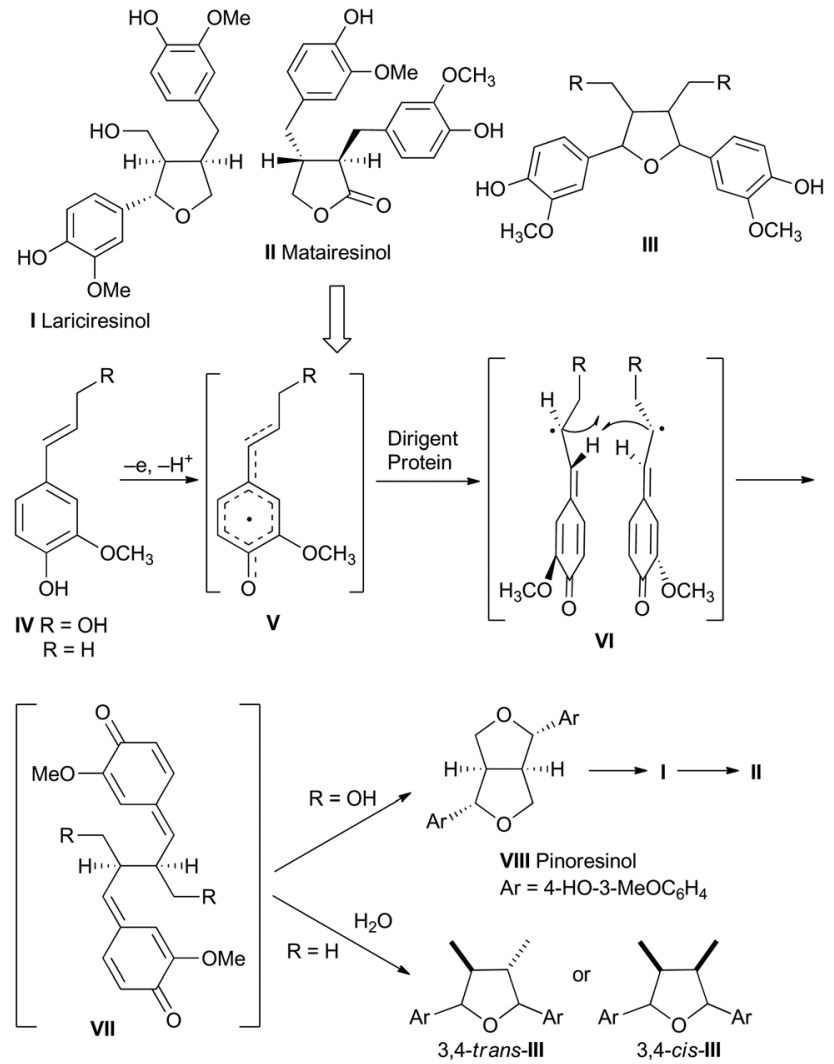

Scheme 1 Major lignan classes containing the tetrahydrofuran ring and their biosynthesis.

aldehydes 2/redox isomerization of resulting alkoxide 3 to enolate 4/Michael addition to 5/radical cyclization/oxygenation process, providing diverse highly functionalized cyclopentane derivatives $6 .^{9}$

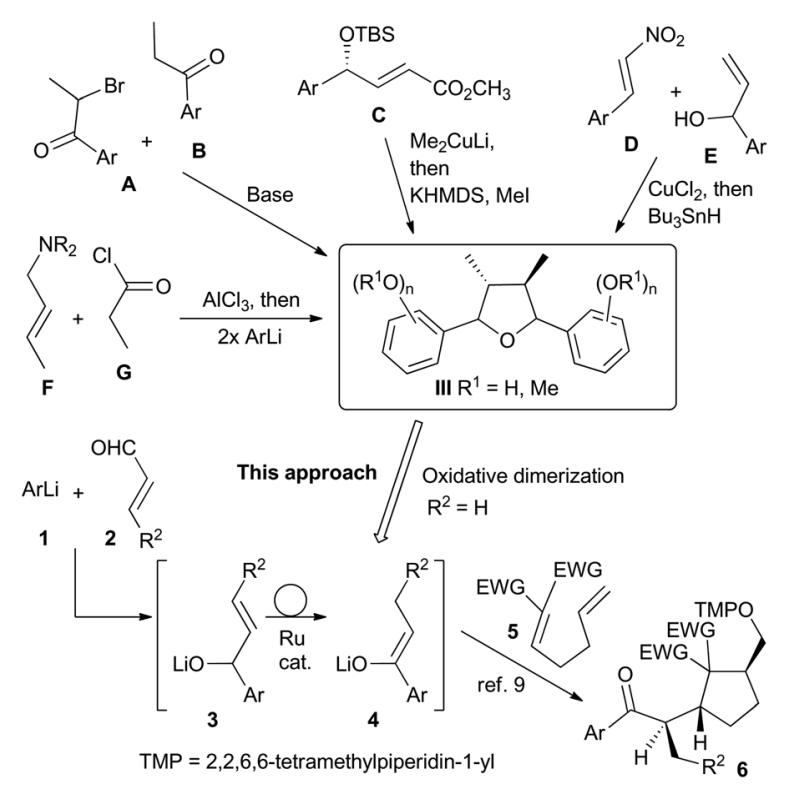

Scheme 2 Previous approaches to tetrahydrofuran lignans III and the proposed bioinspired strategy.
Based on our experience in merging polar and radical processes ${ }^{10}$ we hypothesized that a bioinspired radical-based modular strategy may provide a very short access to tetrahydrofuran lignans III. We envisaged a tandem process consisting of nucleophilic addition of substituted aryllithiums $\mathbf{1}$ to unsaturated aldehydes 2 and subsequent redox isomerization of resulting alkoxides, thus generating enolates 4 . Their single electron oxidation to radicals, similar to that of phenolates IV during biosynthesis ( $c f$. Scheme 1 ), would trigger dimerization to the lignan carbon framework in a single step. ${ }^{11}$

We report here that such tandem organometallic-radical crossover reactions are indeed an efficient strategy to furnish 1,4-diketones with wide scope, good yield, and surprisingly often good diastereoselectivity. They can be transformed in only two further steps to a number of tetrahydrofuran lignans with reasonable diastereoselectivity.

\section{Results and discussion}

An initial screening of new redox isomerization catalysts ${ }^{12}$ revealed that the catalyst system consisting of $\left[\mathrm{Ru}(p \text {-cymene }) \mathrm{Cl}_{2}\right]_{2}$ and $\mathrm{P}(\mathrm{OMe})_{3}$ as a ligand ${ }^{9}$ is most efficient at accomplishing the critical isomerization of alkoxide $\mathbf{3}$ to enolate $\mathbf{4}$ in quantitative yield and the shortest possible reaction time (see the ESI, Table S1†).

With those catalytic conditions at hand, the scope of the tandem addition/isomerization/coupling sequence was explored using ferrocenium hexafluorophosphate ${ }^{13}$ as the oxidant (Table 1). Subjecting phenyllithium and aliphatic $\alpha, \beta$-unsaturated aldehydes 2 to the sequence gave 1,4-diketones 8a-d in good yields and surprisingly good 6-7:1 diastereoselectivity for the coupling of these rather unbiased systems. ${ }^{11,14}$ THF or DME was used with similar results, but the isomerization is faster in higher boiling DME. Cinnamic aldehyde derivatives with a variable substitution pattern at the aryl ring were also applicable, furnishing 2,3-dibenzylic 1,4diketones 8e-i with similar good diastereoselectivities. Even polymerization-sensitive acrolein was applicable in the tandem reactions giving $\mathbf{8 a}, \mathbf{m}-\mathbf{p}$ with reasonable yields and diastereoselectivities. Non-commercial aryllithium reagents were conveniently generated by the lithium-halogen exchange of the corresponding commercial aryl bromides with tert-butyllithium. They underwent the tandem reaction with similar results providing diketones $\mathbf{8 k} \mathbf{-} \mathbf{- p}$. For most oxygenated aryllithium substrates it was better to use THF as the solvent, since the enolates tended to precipitate in DME thus thwarting the subsequent SET oxidation. It was noted that additional alkoxy substituents at the arene ring, such as in $\mathbf{8 h}, \mathbf{8 i}$ and 81-p, led to somewhat decreased, but still reasonable 3-5:1 diastereoselectivities.

The configuration of the minor 1,4-dicarbonyl compounds meso-8d-g and that of major $d / l-\mathbf{8 g}$ were unambiguously determined by X-ray crystallography (Fig. 1). On this basis, the configuration of all other compounds was assigned by NMR spectroscopy. 
Table 1 Tandem nucleophilic addition/redox isomerization/SET oxidation/dimerization reactions (major $d / /$ diastereomer shown) ${ }^{a}$
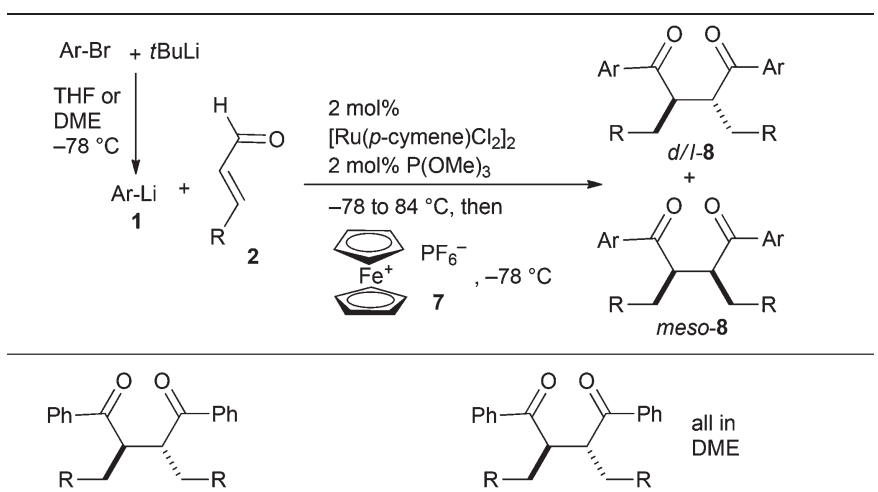

8a $\mathrm{R}=\mathrm{H}, \quad \mathrm{THF}, \quad 62 \%$, dr 6.5:1 8b $R=M e, D M E, 95 \%$, dr $6: 1$ 8c R = Et, DME, $69 \%$, dr 7:1 $8 \mathrm{c}$ R $=\mathrm{Et}, \mathrm{THF}, 84 \%$ dr $6: 1$ 8d R $=\operatorname{Pr}, \mathrm{DME}, 61 \%$, dr $7: 1$<smiles>[R]c1cc(C(=O)C(CC)[C@@H](CC)C(=O)c2ccc(OC)c([R])c2)ccc1OC</smiles>

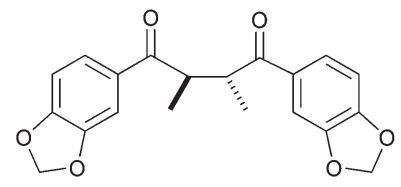

80 THF, 65\%, dr 3:1

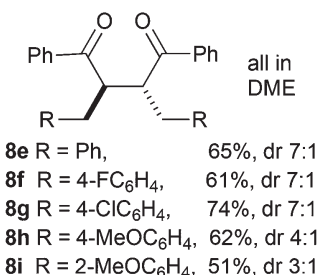

8n $\mathrm{R}^{\prime}=\mathrm{OMe}$, THF, $68 \%$, dr 3:1<smiles></smiles>

8p THF, 41\%, dr 4.5:1

${ }^{a}$ General conditions: $t$ BuLi $(2.6 \mathrm{mmol})$, aryl halide $(1.3 \mathrm{mmol})$ in THF or DME $(8 \mathrm{~mL}),-78{ }^{\circ} \mathrm{C}, 35 \mathrm{~min}$; addition of $2(1.3 \mathrm{mmol}), 15 \mathrm{~min}$, ( $p$-cymene)ruthenium dichloride dimer $(0.026 \mathrm{mmol}), \mathrm{P}(\mathrm{OMe})_{3}$ (0.026 mmol), $5 \mathrm{~min} ; 86^{\circ} \mathrm{C}$, typically $10-20 \mathrm{~min} ; 7(1.5 \mathrm{mmol}),-78^{\circ} \mathrm{C}$.
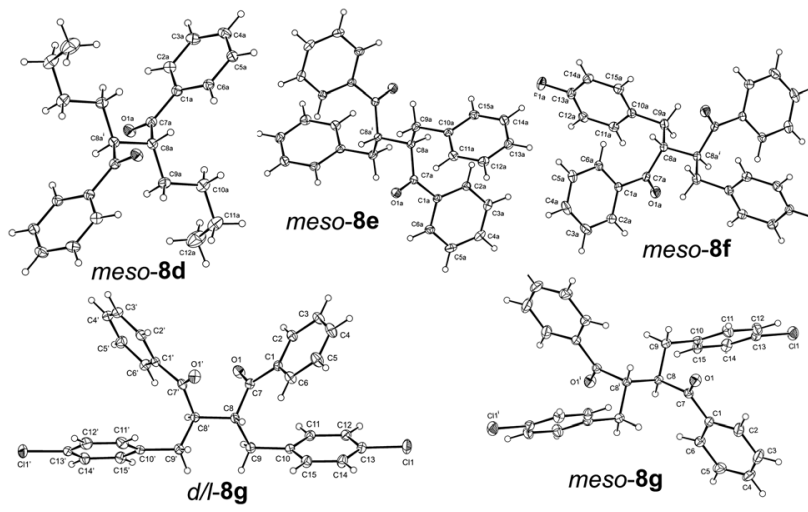

Fig. 1 Structure determination of the minor diastereomers of $\mathbf{8 d}, \mathbf{8 e}$, $\mathbf{8 f}$, and $\mathbf{8 g}$ and the major diastereomer of $\mathbf{8 g}$ by X-ray crystallography. Displacement ellipsoids are drawn at the $30 \%$ probability level.

The mechanistic course of the tandem reaction can be rationalized by nucleophilic 1,2-addition of aryllithiums $\mathbf{1}$ to unsaturated aldehydes $\mathbf{2}$ generating allylic lithium alkoxides $\mathbf{3}$

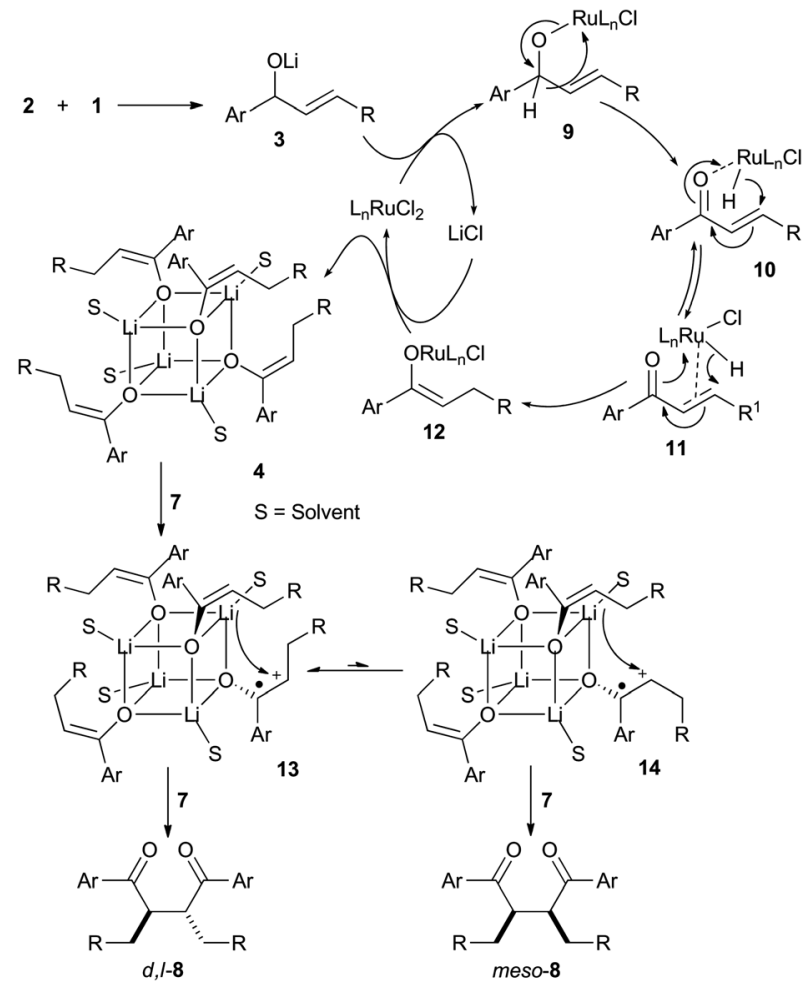

Scheme 3 The mechanistic course of the tandem 1,2-addition/isomerization/radical dimerization reactions.

(Scheme 3). In the presence of the ruthenium catalyst, alkoxide 3 transmetalates to ruthenium alkoxide $\mathbf{9}$, which presumably forms the oxygen-coordinated ruthenium hydride complex 10, which may be in equilibrium with the C-bound hydride complex 11. From both, hydride transfer to the $\beta$-position proceeds, generating ruthenium enolate $\mathbf{1 2}$, which transmetalates back to the corresponding lithium enolate and regenerates the catalyst. The surprising diastereoselectivity of the dimerization is most likely based on the combination of enolate geometry and aggregation effects. We proved previously that the enolates 4 are formed with an exclusive $(Z)$-configuration. ${ }^{9}$ It has also been established that aryl ketone enolates exist in solution as tetrameric aggregates. ${ }^{15}$ The SET oxidation of the aggregate of 4 leads to a tetrameric radical cation 13, in which three enolate units are positioned to add as nucleophiles. Since rotation around the $\mathrm{C}-\mathrm{C}$ bond in radical cation $\mathbf{1 3}$ is still hindered because of its partial double bond character, $d / l-8$ results after $\mathrm{C}-\mathrm{C}$ bond formation and another SET oxidation step (not shown). Minor meso-8 can form by slow rotation to (E)-radical cation 14 and intraaggregate coupling with surrounding enolate units. This proposal is strengthened by Flower's results, who invoked aggregates in oxidative cross-coupling reactions with simple pinacolone enolates. ${ }^{16}$ For oxygenated substrates $\mathbf{8 m}-\mathbf{p}$, alternative aggregate structures involving the phenolic units can also be envisaged, in which the enolate units are not that well aligned for coupling, thus leading to lower diastereomeric ratios. 


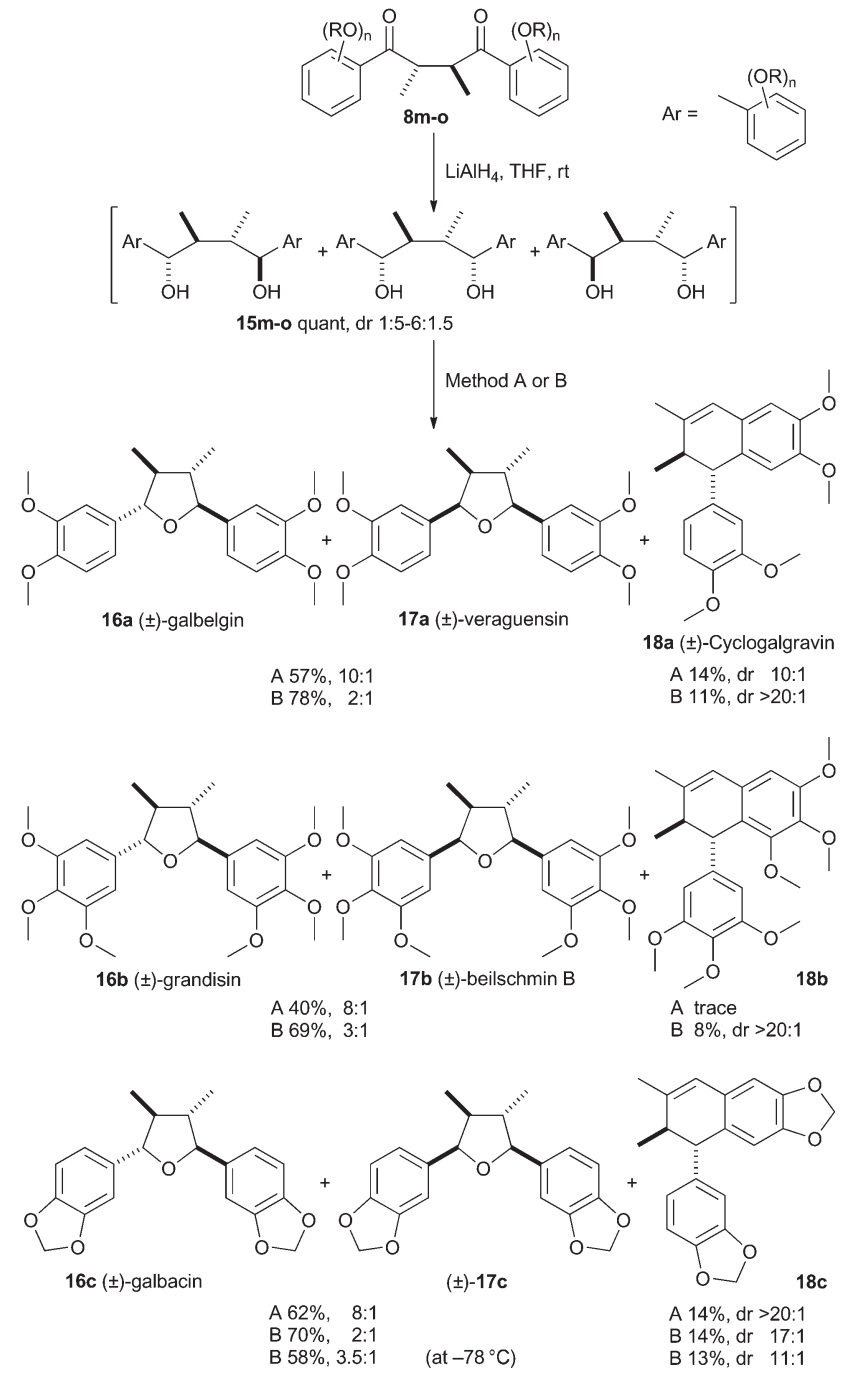

Scheme 4 Total synthesis of tetrahydrofuran lignans 16 and 17 by reduction and cycloetherification. Method $\mathrm{A}: \mathrm{BF}_{3} \cdot \mathrm{OEt}_{2}, \mathrm{CH}_{2} \mathrm{Cl}_{2},-78^{\circ} \mathrm{C}$. Method B: $\mathrm{MsCl}, \mathrm{NEt}_{3}, \mathrm{CH}_{2} \mathrm{Cl}_{2}, 0^{\circ} \mathrm{C}$.

The major $d / l$ diastereomers of 1,4-diketones $\mathbf{8 m - p}$ are convenient precursors for short total syntheses of tetrahydrofuran lignans (Scheme 4). The reduction of all substrates with excess lithium aluminum hydride in THF gave a crude mixture of diols 15 in quantitative yields as a $c a$. 1:1.5:5-6 mixture of symmetrical and unsymmetrical diastereomers (for a stereochemical rationale, see the ESI, Scheme S1 $\dagger$ ). It must be noted that many reduction and hydrogenation methods were tried, but only $\mathrm{LiAlH}_{4}$ at room temperature gave diols 15 without competing formation of lactols and derived side products.

When the crude mixture of diols $\mathbf{1 5 m}-\mathbf{o}$ was subjected to $\mathrm{BF}_{3}$ as the Lewis acid at $-78{ }^{\circ} \mathrm{C}$, trans,trans,trans-tetrahydrofuran lignans $( \pm)$-galbelgin (16a), $( \pm)$-grandisin (16b), or $( \pm)$-galbacin (16c) were isolated with 8-10:1 diastereoselectivity over diastereomeric cis,trans,trans-17a-c (Scheme 4; Method A). Dihydronaphthalene lignans $\mathbf{1 8 a}-\mathbf{c}$, which have also been isolated as natural products, ${ }^{17}$ were formed competitively in low yields. The formation of lignans under these reaction conditions is irreversible, since resubjecting them to $\mathrm{BF}_{3}$ under the reaction conditions did not lead to a change in the ratio (not shown).

The diastereoselectivity for the formation of trans,trans, trans-16a-c was considerably lower, when the cycloetherification was performed by mesylation and intramolecular substitution reactions (Method B) and significant amounts of cis, trans,trans tetrahydrofuran lignans veraguensin (17a), beilschmin B (17b), or unnamed 17c were also isolated. The isolated amounts of dihydronaphthalenes $\mathbf{1 8 a}-\mathbf{c}$ did not change significantly compared to Method A.

The methodology was also applicable to the total synthesis of hydroxy group-containing lignans, such as fragransin $\mathrm{A}_{2}$ (16e), when diketone 8p was used (Scheme 5). Its reduction followed by cycloetherification as described above gave trans, trans,trans-tetrahydrofuran 16d with good diastereoselectivity in the presence of $\mathrm{BF}_{3} \cdot \mathrm{OEt}_{2}$. In contrast, Method $\mathrm{B}$ reproducibly gave low yields of tetrahydrofurans $16 \mathbf{d}$ and $17 d$, but a much larger proportion of dihydronaphthalene 18d. Applying Mitsunobu conditions ${ }^{18}$ for the cycloetherification proved to be more effective at giving $\mathbf{1 6 d}$ and $\mathbf{1 7 d}$ in improved yield, but similar low diastereoselectivity as in Method B. The treatment of tetrahydrofurans $\mathbf{1 6} \mathbf{d}$ and $\mathbf{1 7} \mathbf{d}$ with TBAF provided the natural products fragransin $\mathrm{A}_{2}$ (16e) and odoratisol (17e) in quantitative yield.

The good diastereoselectivity of the cycloetherification reactions mediated by $\mathrm{BF}_{3} \cdot \mathrm{OEt}_{2}$ despite the low $1: 1.5: 5-6$ diastereomeric ratio of diols 15 deserves comment (Scheme 6). The results indicate that it proceeds by a stereoconvergent $\mathrm{S}_{\mathrm{N}} 1$ mechanism, because the diastereomeric ratio of the starting materials is not reflected in the products 16-18, as would

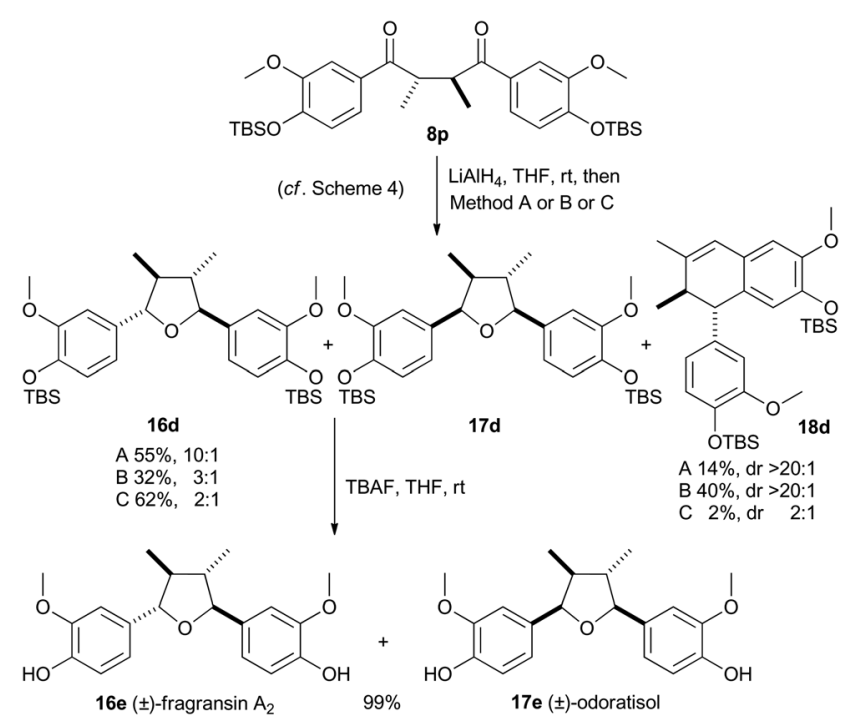

Scheme 5 Total synthesis of phenolic lignans fragransin $A_{2}$ and odoratisol. For Methods A and B, see Scheme 4; Method C: DIAD, PPh, THF, $0{ }^{\circ} \mathrm{C}$ to rt. 

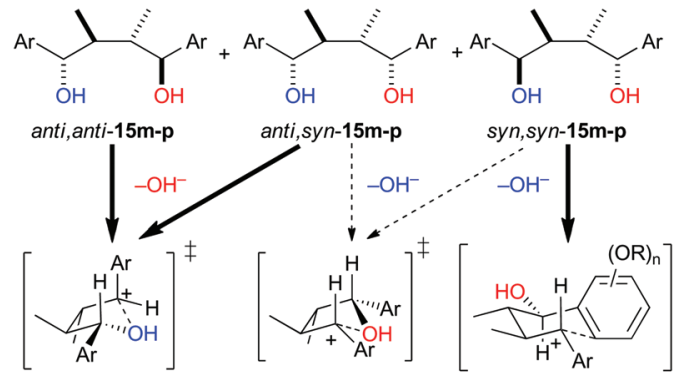

trans,trans,trans-19

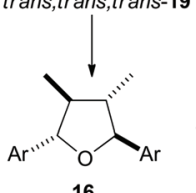

16

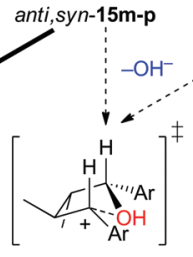

cis,trans,trans-19

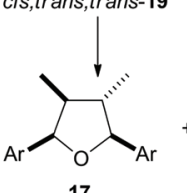

trans, trans, trans-20

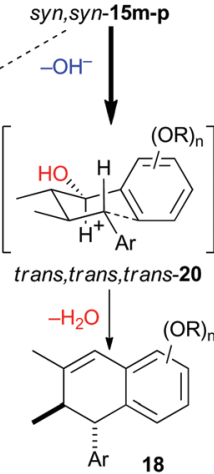

Scheme 6 A stereochemical rationale for the $\mathrm{BF}_{3} \cdot \mathrm{OEt}_{2}$-mediated cycloetherification reactions of diastereomeric diols 15.

be expected in an $\mathrm{S}_{\mathrm{N}}$ 2-type reaction. The Lewis acid $\mathrm{BF}_{3}$ abstracts hydroxide to form quinoid carbenium ions 19. Whereas minor anti,anti-15 can only cyclize via transition state trans,trans,trans-19, the anti-oriented hydroxy group is apparently predominately activated in unsymmetrical anti,syn-19 and cyclization also proceeds via trans,trans,trans-19 to tetrahydrofuran 16. Only small amounts of THF 17 are formed via transition state cis,trans,trans-19, which is higher in energy because of the cis orientation of the arene and the methyl group in the benzylic alcohol part. The minor dihydronaphthalene 18 likely results from the cyclization of minor syn,syn-15. After the elimination of the hydroxy group, a Friedel-Craftstype cyclization via strain-free chair-type transition state trans, trans,trans-20 predominates, thus avoiding energetically higher cis-orientations in transition states, such as cis,trans,trans-19. In contrast, the cyclization of anti,anti- and anti,syn-15 to dihydronaphthalenes $\mathbf{1 8}$ is less likely, since a cis-orientation of hydroxy and methyl groups in the transition state increases its energy (not shown).

The diastereoselectivity of the cycloetherification via the intermediate mesylate (Method B) ${ }^{4,19}$ or using the Mitsunobu conditions (Method $\mathrm{C}$ ) is in contrast more in line with an $\mathrm{S}_{\mathrm{N}} 2$ mechanism, since the configuration of diols 15 is well reflected in the products $\mathbf{1 6}$ and $\mathbf{1 7}$ (for a rationalization see the ESI, Scheme $\mathrm{S} 2 \dagger$ ). This reasoning is also supported by the fact that the diastereoselectivity of the cycloetherification remains similar on lowering the temperature to $-78{ }^{\circ} \mathrm{C}$ and remains significantly different from that of the $\mathrm{BF}_{3}$-mediated cyclization. These results are important concerning the biosynthetic origin of the stereochemically diverse tetrahydrofuran lignans ( $c f$. Scheme 1), since the results point to the fact that the configuration of the natural products is not determined by the unconstrained conformational preferences of the carbocationic intermediates as described here, but rather by the conformation enforced by the involved dirigent protein or enzyme. ${ }^{2,20}$

\section{Conclusions}

In summary, a very short, modular and stereoconvergent synthesis of tetrahydrofuran lignans is reported. A key step for the construction of the carbon framework is the new tandem nucleophilic addition/ruthenium-catalyzed isomerization/SET oxidation/radical dimerization resulting in 1,4-dicarbonyl compounds with moderate to good diastereoselectivity, which is traced to the aggregation behavior of the intermediate enolates. The present approach has the potential to generate 1,4diketones with wider scope than existing methodologies. They are easily transformed into the tetrahydrofuran core by reduction and cycloetherification, which proceed with good diastereoselectivity under $\mathrm{S}_{\mathrm{N}} 1$ conditions. These results are interesting with respect to the biosynthetic origin of tetrahydrofuran lignans, where carbocations are supposed to be involved as in the presented results, suggesting that the involved proteins enforce the conformation of the cyclizing substrate to the species-specifically formed stereochemically diverse THF lignans.

\section{Conflicts of interest}

There are no conflicts to declare.

\section{Acknowledgements}

Generous financial support from the Institute of Organic Chemistry and Biochemistry of the Czech Academy of Sciences (RVO:61388963), the Gilead Sciences Research Center at IOCB and the Grant Agency of the Czech Republic (P203/09/1936) is gratefully acknowledged. I. C. thanks the Ministry of Education, Youth and Sports of the Czech Republic (MSM0021620857) for financial support.

\section{Notes and references}

1 (a) S. Suzuki and T. Umezawa, J. Wood Sci., 2007, 53, 273284; (b) L. B. Davin, M. Jourdes, A. M. Patten, K.-W. Kim, D. G. Vassão and N. G. Lewis, Nat. Prod. Rep., 2008, 25, 1015-1090; (c) J. Zhang, J. Chen, Z. Liang and C. Zhao, Chem. Biodiversity, 2014, 11, 1-54; (d) M. Saleem, H. J. Kim, M. S. Ali and Y. S. Lee, Nat. Prod. Rep., 2005, 22, 696-716; (e) R. S. Ward, Nat. Prod. Rep., 1999, 16, 75-96; (f) C. S. Ramos, H. V. Linnert, M. M. de Moraes, J. H. do Amaral, L. F. Yamaguchi and M. J. Kato, RSC Adv., 2017, 7, 46932-46937.

2 (a) Lignin and Lignan Biosynthesis, ed. N. G. Lewis and S. Sarkanen, ACS Symposium Series, 1998, vol. 697; (b) L. B. Davin and N. G. Lewis, Phytochem. Rev., 2003, 2, 257-288; (c) T. Umezawa, Phytochem. Rev., 2003, 2, 371-390; (d) T. Umezawa, M. Yamamura, T. Nakatsubo, S. Suzuki and T. Hattori, Recent Adv. Phytochem., 2011, 41, 179-197. 
3 (a) T. Biftu, B. G. Hazra, R. Stevenson and J. R. Williams, J. Chem. Soc., Perkin Trans. 1, 1978, 1147-1150; (b) C. W. Perry, M. V. Kalnins and K. H. Deitcher, J. Org. Chem., 1972, 37, 4371-4376.

4 (a) S. Hanessian, G. J. Reddy and N. Chahal, Org. Lett., 2006, 8, 5477-5480; (b) S. Hanessian and G. J. Reddy, Synlett, 2007, 475-479.

5 (a) U. Jahn and D. Rudakov, Org. Lett., 2006, 8, 4481-4484; (b) U. Jahn and D. Rudakov, Synlett, 2004, 1207-1210; (c) S. Martinet, A. Méou and P. Brun, Eur. J. Org. Chem., 2009, 2306-2311; (d) P. F. Schatz, J. Ralph, F. Lu, I. A. Guzei and M. Bunzel, Org. Biomol. Chem., 2006, 4, 28012808.

6 (a) R. Stevenson and J. R. Williams, Tetrahedron, 1977, 33, 285-288; (b) R. Ahmed, F. G. Schreiber, R. Stevenson, J. R. Williams and H. M. Yeo, Tetrahedron, 1976, 32, 13391344.

7 (a) C. E. Rye and D. Barker, Synlett, 2009, 3315-3319; (b) C. E. Rye and D. Barker, J. Org. Chem., 2011, 76, 66366648.

8 Reviews: (a) R. Uma, C. Crevisy and R. Gree, Chem. Rev., 2003, 103, 27-51; (b) V. Cadierno, P. Crochet and J. Gimeno, Synlett, 2008, 1105-1124; (c) T. D. Sheppard, Synlett, 2011, 1340-1344; (d) N. Ahlsten, A. Bartoszewicz and B. Martin-Matute, Dalton Trans., 2012, 41, 1660-1670. Asymmetric: (e) N. Arai, K. Sato, K. Azuma and T. Ohkuma, Angew. Chem., Int. Ed., 2013, 52, 7500-7504. Propargylic alcohols: $(f)$ V. Cadierno, P. Crochet, S. E. Garcia-Garrido and J. Gimeno, Dalton Trans., 2010, 39, 4015-4031.

9 P. R. Jagtap, L. Ford, E. Deister, R. Pohl, I. Císařová, J. Hodek, J. Weber, R. Mackman, G. Bahador and U. Jahn, Chem. - Eur. J., 2014, 20, 10298-10304.

10 (a) U. Jahn, Chem. Commun., 2001, 1600-1601; (b) M. Holan, R. Pohl, I. Císařová, B. Klepetářová, P. G. Jones and U. Jahn, Chem. - Eur. J., 2015, 21, 98779888; (c) F. Kafka, M. Holan, D. Hidasová, R. Pohl, I. Císařová, B. Klepetářová and U. Jahn, Angew. Chem., Int. Ed., 2014, 53, 9944-9948; (d) U. Jahn and E. Dinca, J. Org. Chem., 2010, 75, 4480-4491; (e) U. Jahn, F. Kafka, R. Pohl and P. G. Jones, Tetrahedron, 2009, 65, 10917-10929.

11 Reviews on oxidative dimerizations: (a) A. G. Csaky and J. Plumet, Chem. Soc. Rev., 2001, 30, 313-320; (b) C. S. Yeung and V. M. Dong, Chem. Rev., 2011, 111, 1215-1292; (c) F. Guo, M. D. Clift and R. J. Thomson, Eur. J. Org. Chem., 2012, 4881-4896. Newer results: (d) T. Amaya, T. Masuda, Y. Maegawa and T. Hirao, Chem. Commun., 2014, 50, 2279-2281; (e) S. Mao, Y.-R. Gao, S.-L. Zhang, D.-D. Guo and Y.-Q. Wang, Eur. J. Org. Chem., 2015, 876-885.
12 S. Manzini, A. Poater, D. J. Nelson, L. Cavallo and S. P. Nolan, Chem. Sci., 2014, 5, 180-188.

13 (a) Review: S. Toma and R. Sebesta, Synthesis, 2015, 16831695; (b) D. A. Khobragade, S. G. Mahamulkar, L. Pospišil, I. Císařová, L. Rulíšek and U. Jahn, Chem. - Eur. J., 2012, 18, 12267-12277; (c) U. Jahn and P. Hartmann, J. Chem. Soc., Perkin Trans. 1, 2001, 2277-2282; (d) E. Dinca, P. Hartmann, J. Smrček, I. Dix, P. G. Jones and U. Jahn, Eur. J. Org. Chem., 2012, 4461-4482; (e) T. Amatov, R. Pohl, I. Císařová and U. Jahn, Angew. Chem., Int. Ed., 2015, 54, 12153-12157; (f) L. Řehová, M. Dračinský and U. Jahn, Org. Biomol. Chem., 2016, 14, 9612-9621; $(g)$ J. Smrček, R. Pohl and U. Jahn, Org. Biomol. Chem., 2017, 15, 9408-9414.

14 For sterically strongly biased diastereoselective dimerizations: (a) E. S. Krygowski, K. Murphy-Benenato and M. D. Shair, Angew. Chem., Int. Ed., 2008, 47, 1680-1684; (b) F. Guo, L. C. Konkol and R. J. Thomson, J. Am. Chem. Soc., 2011, 133, 18-20; (c) A. S. Lee and M. D. Shair, Org. Lett., 2013, 15, 2390-2393.

15 (a) L. R. Liou, A. J. McNeil, A. Ramirez, G. E. S. Toombes, J. M. Gruver and D. B. Collum, J. Am. Chem. Soc., 2008, 130, 4859-4868; (b) K. J. Kolonko, M. M. Biddle, I. A. Guzei and H. J. Reich, J. Am. Chem. Soc., 2009, 131, 11525-11534; (c) K. J. Kolonko, D. J. Wherritt and H. J. Reich, J. Am. Chem. Soc., 2011, 133, 16774-16777; (d) H. J. Reich, Chem. Rev., 2013, 113, 7130-7178; (e) J. M. Gruver, L. R. Liou, A. J. McNeil, A. Ramirez and D. B. Collum, J. Org. Chem., 2008, 73, 7743-7747.

16 B. M. Casey and R. A. Flowers II, J. Am. Chem. Soc., 2011, 133, 11492-11495.

17 (a) Y. Peng, Z.-B. Luo, J.-J. Zhang, L. Luo and Y.-W. Wang, Org. Biomol. Chem., 2013, 11, 7574-7586; (b) A. de Melo Bezerra, A. C. da Silva Lins, P. Filgueiras de Athayde-Filho, M. S. da Silva, J. M. Barbosa-Filho, C. A. Camara, T. M. Sarmento Silva, V. da Silva Luna and C. Figueredo dos Santos, Quim. Nova, 2012, 35, 2226-2228.

18 (a) For applications with donor-substituted benzylic alcohols, see: K. Harada, M. Kubo, H. Horiuchi, A. Ishii, T. Esumi, H. Hioki and Y. Fukuyama, J. Org. Chem., 2015, 80, 7076-7088; (b) R. F. C. Brown, W. R. Jackson and T. D. McCarthy, Tetrahedron, 1994, 50, 5469-5488; (c) R. F. C. Brown, W. R. Jackson and T. D. McCarthy, Tetrahedron Lett., 1993, 34, 1195-1196; (d) A. V. Malkov, M. Barłgó, L. Miller-Potucká, M. A. Kabeshov, L. J. Farrugia and P. Kočovský, Chem. - Eur. J., 2012, 18, 6873-6884.

19 E. K. Jung, N. Dittrich, L. I. Pilkington, C. E. Rye, E. Leung and D. Barker, Tetrahedron, 2015, 71, 9439-9456.

20 N. P. Lopes, M. Yoshida and M. J. Kato, Braz. J. Pharm. Sci., 2004, 40, 53-57. 